\title{
The Differences Between the Right and Left Side Laparoscopic Donor Nephrectomy Outcomes: A Comparative Analysis of Single-Center Outcomes
}

\author{
(1) Kadir Omur Gunseren,' (1) Mehmet Cagatay Cicek, (1) Yavuz Mert Aydin, ${ }^{1}$ (1) Cagdas Gokhun Ozmerdiven, ${ }^{2}$ \\ (1) Ismet Yavascaoglu'
}

'Department of Urology, Bursa Uludag University Faculty of Medicine, Bursa, Turkey

${ }^{2}$ Department of Urology, İstanbul Aydın University Faculty of Medicine, Istanbul, Turkey

\begin{abstract}
Objective: This study aimed to compare the right and left side laparoscopic donor nephrectomy (LDN) outcomes of a single center. Materials and Methods: The outcomes of patients who underwent LDN in our clinic between 2008 and 2020 were evaluated retrospectively. Two groups were consisted according to the side of the donor kidney. The gender, age, body mass index, duration of operation, amount of bleeding, warm ischemia time, drain removal time, and duration of hospitalization and complications were compared between groups.

Results: A total of 314 patients were included in the study. Sixty-six patients underwent right LDN and 248 underwent left LDN. There was no difference between groups in terms of age, duration of operation, amount of bleeding, warm ischemia time, and complications $(p>0.05)$. However, drain removal time and duration of hospitalization were longer in the left LDN group $(p<0.05)$. Conclusions: The right LDN had similar intraoperative outcomes with the left LDN. However, failure on meticulous dissection of the lymphatic structures during left LDN might cause chylous drainage and prolonged hospitalization time.

Keywords: Donor nephrectomy; kidney transplantation; laparoscopic.

Please cite this article as: Gunseren KO, Cicek MC, Aydin YM, Ozmerdiven CG, Yavascaoglu. The Differences Between the Right and Left Side Laparoscopic Donor Nephrectomy Outcomes: A Comparative Analysis of Single-Center Outcomes. Med Bull Sisli Etfal Hosp 2021;55(3):339-343.
\end{abstract}

\section{Introduction}

The laparoscopic approach for live donor nephrectomy was first described in 1995. ${ }^{[1]}$ Today, laparoscopic donor nephrectomy (LDN) with less post-operative pain, shorter hospital stay and similar graft survival rates with the open approach is the preferred routine procedure in many centers..$^{[2-4]}$
There is a significant independent relationship between inflammation markers such as leucocyte count, neutrophil count, CRP, interleukin, and TNF-a. ${ }^{[9,10]}$ In addition, neutrophil-to-lymphocyte ratio (NLR) is considered to be a marker of subclinical inflammation which is associated with morbidity and mortality in diabetic patients. ${ }^{[11,12]}$ 
There is a tendency to prefer the left kidney as the LDN side due to anatomical differences between the right and left kidney. ${ }^{[5]}$ However, there are varying results regarding the intraoperative and post-operative outcomes of the right and left LDN. According to some reports, LDN is technically easier; on the other hand, some reports state that right LDN has some advantages such as shorter operation time or less bleeding. ${ }^{[4,6]}$ Therefore, we aimed to compare the intraoperative and postoperative outcomes of patients who underwent laparoscopic right and left donor nephrectomy in our clinic.

\section{Materials and Methods}

Outcomes of the patients who underwent LDN in our clinic between 2008 and 2010 were evaluated retrospectively after obtaining approval from the local ethics committee. Before choosing the side to be performed donor nephrectomy, all patients were assessed with spiral computed tomographic angiography for renal vascular anatomy and with dimercaptosuccinic acid scan for renal function. Donors with urolithiasis or congenital renal anomalies were excluded from the study. The pelvic vascular structures of the grafts were evaluated with the ultrasonic examination.

Patients were classified into two groups according to the side of surgery. Demographic characteristics such as gender, age and body mass index (BMI), and intraoperative outcomes such as operation time, amount of bleeding (measured liquid in the aspirator), warm ischemia time, and complications were compared. BMI was calculated by dividing the weight $(\mathrm{kg})$ by the height $\left(\mathrm{m}^{2}\right)$. The differences between the groups' pre-operative and post-operative $1^{\text {st }}$-day creatinine levels, drain removal times, and hospitalization times were compared. Early post-operative complications were classified using the Clavien-Dindo scoring system as recommended by the European Association of Urology guideline. Intraoperative and early post-operative complications were compared between groups. ${ }^{[7]}$

All procedures were performed with the transperitoneal method. Pneumoperitoneum was created using a veress needle after the patient was put in a lateral decubitus position. Two $12 \mathrm{~mm}$ and one $5 \mathrm{~mm}$ trocar were placed under direct vision after a $12 \mathrm{~mm}$ trocar was placed lateral to the rectus muscle to be used as the camera port. $A 5 \mathrm{~mm}$ additional port was located for the retraction of the liver during the right LDN. An oblique paramedian incision was made to extract the kidney following the complete mobilization of the kidney. The ureter was divided at the level of iliac vessels. The renal artery was controlled using Endo-GIATM (Covidien LLC, Mansfield, MA, USA) vascular stapler in the right and left LDN. The left renal vein was controlled using hem-o-lok clips. The right renal vein was controlled using another Endo-GIATM (Covidien LLC, Mansfield, MA, USA) vascular stapler.

\section{Statistical Analysis}

Data were analyzed using the SPSS package software program for Windows (SPSS, Inc., Chicago, IL USA). The distribution of data was assessed with the Kolmogorov-Smirnov Test. The normally distributed data were analyzed using the independent Sample $t$-test. The Mann-Whitney U-Test was used to analyze data that did not show normal distribution. Results were presented as mean \pm SD and median (minimum-maximum). The Chi-square or Fisher Exact tests were used to evaluate categorical variables. $p<0.05$ was considered significant.

\section{Results}

A total of 314 patients were included in the study. Sixtysix patients underwent right and 248 underwent left LDN. The demographic characteristics and intraoperative outcomes of the groups are presented in Table 1. The mean operation time was $138 \pm 35.8 \mathrm{~min}$ in the right LDN group and $139 \pm 41.5 \mathrm{~min}$ in the left $(p=0.935)$. The amount of bleeding was $56.5 \pm 38.7 \mathrm{ml}$ and $57.3 \pm 40.9 \mathrm{ml}$ in the right and left LDN groups, respectively $(p=0.785)$. The warm ischemia time was $138.6 \pm 82.2 \mathrm{~min}$ in the right LDN group and $117.8 \pm 50.5 \mathrm{~min}$ in the left $(p=0.075)$.

The post-operative outcomes of the groups are presented in Table 2. The changes between pre-operative and post-operative creatinine levels were $0.2 \pm 0.1 \mathrm{mg} / \mathrm{dl}$ and $0.2 \pm 0.2$ $\mathrm{mg} / \mathrm{dl}$ in the right LDN and left LDN groups, respectively $(p=0.501)$. The right LDN group had a significantly shorter drain removal time than the left LDN group $(1.7 \pm 0.9$ and $2 \pm 1.4$ days, respectively, $p=0.045$ ). In addition, the length of hospital stay was significantly shorter in the right LDN group than in the left LDN group (2.9 \pm 1.1 and $3.4 \pm 1.7$ days, respectively, $p=0.013$ ).

The complications are presented in Table 3. There was no difference between groups' intraoperative and post-operative complication rates ( $p=0.372$ and $p=0.658$, respectively). Intraoperative bleeding was observed in three cases in the right LDN and five cases in the left LDN groups. All hemorrhagic complications were managed laparoscopically; however, one case in the LDN group was converted to open due to the rotation of the kidney. In the post-operative period, one patient in the right LDN group was followed up in the intensive care unit for 1 day as a result of respiratory depression (Clavien Grade 4). Moreover, one patient in the left LDN group experienced hemorrhagic drainage requiring 
Table 1. Comparison of the demographic characteristics and intraoperative outcomes of the groups

\begin{tabular}{|c|c|c|c|}
\hline & $\begin{array}{c}\text { Right LND ( } \mathrm{n}=66) \\
\text { mean } \pm \text { SD } \\
\text { median (min-max) }\end{array}$ & $\begin{array}{l}\text { Left LND }(n=248) \\
\text { mean } \pm \text { SD } \\
\text { median (min-max) }\end{array}$ & $p$ \\
\hline \multicolumn{4}{|l|}{ Gender } \\
\hline Female $n(\%)$ & $45(68.2)$ & $135(54.4)$ & $0.045^{\mathrm{ch}}$ \\
\hline Male $n(\%)$ & $21(31.8)$ & $113(45.6)$ & \\
\hline \multirow[t]{2}{*}{ Age } & $50.1 \pm 13.2$ & $51.3 \pm 11$ & $0.450^{t}$ \\
\hline & $50(20-76)$ & $51(24-80)$ & \\
\hline \multirow[t]{2}{*}{ BMI } & $26.2 \pm 6.3$ & $27.9 \pm 4.5$ & $0.264^{t}$ \\
\hline & $25.4(17.6-39.4)$ & $27.4(17.5-38.7)$ & \\
\hline \multirow[t]{2}{*}{ Operation Time (min) } & $138 \pm 35.8$ & $139 \pm 41.5$ & $0.935^{\mathrm{m}}$ \\
\hline & $142(70-210)$ & $150(30-390)$ & \\
\hline \multirow[t]{2}{*}{ Bleeding (ml) } & $56.5 \pm 38.7$ & $57.3 \pm 40.9$ & $0.785^{\mathrm{m}}$ \\
\hline & $50(10-200)$ & $50(10-250)$ & \\
\hline \multirow[t]{2}{*}{ Warm Ischemia Time (s) } & $138.6 \pm 82.2$ & $117.8 \pm 50.5$ & $0.075^{m}$ \\
\hline & $110(30-450)$ & $97(45-400)$ & \\
\hline
\end{tabular}

Table 2. Comparison of the postoperative outcomes in groups

\begin{tabular}{|c|c|c|c|}
\hline & $\begin{array}{c}\text { Right LDN (66) } \\
\text { mean } \pm \text { SD } \\
\text { median (min-max) }\end{array}$ & $\begin{array}{c}\text { Left LDN (248) } \\
\text { mean } \pm S D \\
\text { median (min-max) }\end{array}$ & $p$ \\
\hline $\begin{array}{l}\text { Pre-operative and post-operative creatinine } \\
\text { differences }(\mathrm{mg} / \mathrm{dl})\end{array}$ & $\begin{array}{c}0.2 \pm 0.1 \\
0.2(-1-0.7)\end{array}$ & $\begin{array}{c}0.2 \pm 0.2 \\
0.2(-0.4-1.1)\end{array}$ & $0.501^{\mathrm{m}}$ \\
\hline Drain removal time (day) & $\begin{array}{l}1.7 \pm 0.9 \\
2(1-6)\end{array}$ & $\begin{array}{c}2 \pm 1.4 \\
2(1-16)\end{array}$ & $0.045^{\mathrm{m}}$ \\
\hline Duration of hospitalization (day) & $\begin{array}{l}2.9 \pm 1.1 \\
3(1-6)\end{array}$ & $\begin{array}{l}3.4 \pm 1.7 \\
3(1-17)\end{array}$ & $0.013^{m}$ \\
\hline
\end{tabular}

LDN: Laparoscopic donor nephrectomy; SD: Standard deviation; m: Mann-Whitney U-Test.

transfusion (Clavien Grade 2), two patients had prolonged ileus (Clavien Grade 2), wound hematoma (Clavien Grade 1) was seen in one patient, and prolonged chylous drainage (Clavien Grade 2) was observed in two. All post-operative complications were managed conservatively.

\section{Discussion}

Kidney transplantation can be preferred as one of the treatment options for some patients with end-stage renal failure due to its cost-effective and sound nature ${ }^{[8]}$ Kidney transplantations from living donors provide better graft survival than cadaveric kidneys and significantly shortened organ transplantation waiting time. ${ }^{[9]} \mathrm{LDN}$ has become the preferred approach in many centers as a safe alternative to open surgery after its first usage to reduce morbidity in donor patients. ${ }^{[5,10]}$

Many parameters are evaluated in choosing the side for LDN. If possible, the common method is to remove the left kidney as the shorter right renal vein may make the recipient's operation more complicated. ${ }^{[5]}$ However, the right LDN may be preferred in some situations such as having multiple left renal arteries, better left renal function or pathologies at the right kidney such as angiomyolipoma or urolithiasis. ${ }^{[5,6]}$

According to some studies, the right LDN has a shorter operation time than the left LDN. ${ }^{[5,1]]}$ The mean operation times of the groups were similar in our study. Furthermore, the mean amounts of bleeding were similar in both groups. 
Table 3. Intraoperative and post-operative complications in the groups

\begin{tabular}{|c|c|c|c|}
\hline & $\begin{array}{c}\text { Right LDN (66) } \\
\text { mean } \pm \text { SD } \\
\text { median (min-max) }\end{array}$ & $\begin{array}{c}\text { Left LDN (248) } \\
\text { mean } \pm \text { SD } \\
\text { median (min-max) }\end{array}$ & $p$ \\
\hline \multicolumn{4}{|c|}{ Intraoperative complications (n) } \\
\hline Renal vein injury & 1 & & $0.372^{\mathrm{ch}}$ \\
\hline Vena cava / Aort injury & 1 & 1 & \\
\hline Adrenal vein injury & 1 & 2 & \\
\hline Rotation of kidney & & 1 & \\
\hline Lomber vein injury & & 1 & \\
\hline \multicolumn{4}{|c|}{ Post-operative Complications ( $\mathrm{n}$ ) } \\
\hline Respiratory depression & 1 & & $0.658^{\mathrm{ch}}$ \\
\hline Bleeding & & 1 & \\
\hline Prolonged ileus & & 2 & \\
\hline Hematoma at the wound & & 1 & \\
\hline Prolonged chylous drainage & & 2 & \\
\hline
\end{tabular}

In a meta-analysis, Wang et al. reported shorter operation time and less bleeding for the right LDN; however, these differences were not clinically significant. ${ }^{[4]}$ They recommended using the left kidney in clinical practice since the longer renal vein of the left kidney could facilitate the recipient's procedure. ${ }^{[4]}$ We preferred the left LDN in our clinic in the absence of contraindications.

Prolonged warm ischemia time during LDN may affect the graft functions by increasing intrarenal microthrombus development risk. ${ }^{[12]}$ Hence, the warm ischemia time during LDN should be as short as possible. The duration of warm ischemia changed between three to $10 \mathrm{~min}$ in the LDN series in the literature. ${ }^{[13]}$ The warm ischemia times were in line with the literature and between $30 \mathrm{~s}$ and 7.5 min in the present study. Warm ischemia times were similar for right and left LDN. ${ }^{[4,5]}$ Similarly, we did not find significant differences in warm ischemia times.

In the meta-analysis of Wang et al., the intraoperative complications during left LDN were more common than the right LDN. ${ }^{[4]}$ Regardless, these intraoperative complications were caused due to the more complex anatomic structures surrounding the left kidney and not considered to be severe events that can affect the operation. ${ }^{[4]}$ We found similar intraoperative complication rates between the right and left LDN groups. The intraoperative complications in the present study were associated with vascular structures such as a renal vein, adrenal vein, vena cava, or aorta but not related to surrounding organs such as the bowel, pancreas, spleen, or liver.
There were no differences between both sides in terms of post-operative complications. However, the left LDN had slightly more postoperative complications than the right. The drain removal time and duration of hospitalization were longer in the left LDN group. Chylous leakage may develop after left LDN. ${ }^{[14]}$ In our series, two patients in the left LDN group experienced chylous leakage. The delay in drain removal time due to chylous leakage in the left LDN group was the main reason for the different duration of hospital stay between the groups. The lymphatic tissues should be exposed with meticulous dissections and controlled with bipolar cautery or clips to prevent lymphatic leakage. ${ }^{[14,15]}$ In the light of these findings, it can be say that left LDN might be more advantageous than right, because of providing longer renal vein and having similar outcomes and complication rates to the right LDN; however, meticilous dissection of lympatics should not be neglected.

The function grades of the donor's kidneys are one of the parameters when the side of donor nephrectomy is determined. The kidney with less function should be chosen for donor nephrectomy ${ }^{[16]}$ This parameter is considered when we decide the side in our clinic. Consistent with the literature, the changes in the pre-operative and post-operative creatinine values in our series were similar between the groups. Thereby, if an adequate preoperative evaluation is performed, there is no difference between removing the right or left kidney in terms of compensating the removed kidney in the early post-operative period. In the present study, there was a difference in gender between the two 
groups. Peracha et al. reported women to donate more organs than men and gender disparity in living kidney donation. ${ }^{[17]}$ Various speculative comments can be made on this issue. However, the gender disparity between the right and left LDN groups may be a coincidence, and this issue should be investigated with differently designed studies.

The present study had some limitations. First, it is a retrospective designed study. Second is the lower number of right LDN than the left side. Third is having no examination about the long-term graft results.

\section{Conclusions}

Right LDN has similar intraoperative outcomes with the left LDN. However, failure in the meticulous dissection of the lymphatic structures during the left LDN may result in chylous drainage and prolonged hospitalization time.

\section{Disclosures}

Ethics Committee Approval: Uludag University Faculty of Medicine Clinical Research Ethics Committee (No: 2020-23/24 December 23 2020).

Peer-review: Externally peer-reviewed.

Conflict of Interest: None declared.

Authorship Contributions: Concept - K.O.G.; Design - K.O.G.; Supervision - I.Y.; Materials - M.C.C.; Data collection \&/or processing - Y.M.A., C.G.O.; Analysis and/or interpretation K.O.G., C.G.O.; Literature search - K.O.G., M.C.C.; Writing - K.O.G.; Critical review - I.Y.

\section{References}

1. Ratner LE, Ciseck LJ, Moore RG, Cigarroa FG, Kaufman HS, Kavoussi LR. Laparoscopic live donor nephrectomy. Transplantation 1995;60:1047-9.

2. Giessing M. Laparoscopic living-donor nephrectomy. Nephrol Dial Transplant 2004;19. [CrossRef]

3. Shockcor NM, Sultan S, Alvarez-Casas J, Brazio PS, Phelan M, LaMattina JC, et al. Minimally invasive donor nephrectomy: current state of the art. Langenbecks Arch Surg 2018;403:681-91. [CrossRef]

4. Wang K, Zhang P, Xu X, Fan M. Right versus left laparoscopic living-donor nephrectomy: a meta-analysis. Exp Clin Transplant 2015;13:214-26.

5. Kumar A, Chaturvedi S, Gulia A, Maheshwari R, Dassi V, Desai P. Laparoscopic live donor nephrectomy: comparison of outcomes right versus left. Transplant Proc 2018;50:2327-32. [CrossRef]
6. Mandal AK, Cohen C, Montgomery RA, Kavoussi LR, Ratner LE. Should the indications for laparascopic live donor nephrectomy of the right kidney be the same as for the open procedure? Anomalous left renal vasculature is not a contraindiction to laparoscopic left donor nephrectomy. Transplantation 2001;71:660-4. [CrossRef]

7. Mitropoulos D, Artibani W, Graefen M, Remzi M, Rouprêt M, Truss MC. EAU Guidelines on Reporting and Grading of Complications after Urologic Surgical Procedures 2016. Available at: https:// uroweb.org/wp-content/uploads/EAU-Guidelines-ReportingComplications-2016.pdf. Accessed Jun 14, 2021.

8. Ferhatoğlu MF, Kartal A, Kıvılcım T, Filiz Aí, Kebudi A, Gürkan A. Retrospective analysis of the first 100 kidney transplants at the Istanbul Okan University, Health Application and Research Center. Sisli Etfal Hastan Tip Bul 2019;53:221-7. [CrossRef]

9. Schussler L, Khetan P, Peacock M, Dickstein E, LaPointe-Rudow $D$, Palese $M$, et al. Is obesity a contraindication for kidney donation? Surg Endosc 2020;34:4632-7. [CrossRef]

10. Nanidis TG, Antcliffe D, Kokkinos C, Borysiewicz CA, Darzi AW, Tekkis PP, et al. Laparoscopic versus open live donor nephrectomy in renal transplantation: a meta-analysis. Ann Surg 2008;247:58-70. [CrossRef]

11. KashiwadateT,Tokodai K, Amada N, Haga I, Takayama T, Nakamura A, et al. Right versus left retroperitoneoscopic living-donor nephrectomy. Int Urol Nephrol 2015;47:1117-21. [CrossRef]

12. Friedersdorff F, Wolff I, Deger S, Roigas J, Buckendahl J, Cash H, et al. No need for systemic heparinization during laparoscopic donor nephrectomy with short warm ischemia time. World J Urol 2011;29:561-6. [CrossRef]

13. Stamatakis L, Mercado MA, Choi JM, Sanchez EJ, Gaber AO, Knight RJ, et al. Comparison of laparoendoscopic single site (LESS) and conventional laparoscopic donor nephrectomy at a single institution. BJU Int 2013;112:198-206. [CrossRef]

14. Capocasale E, laria M, Vistoli F, Signori S, Mazzoni MP, Dalla Valle $\mathrm{R}$, et al. Incidence, diagnosis, and treatment of chylous leakage after laparoscopic live donor nephrectomy. Transplantation 2012;93:82-6. [CrossRef]

15. Guglielmo N, Melandro F, Nudo F, Mennini G, Levi Sandri GB, Berloco PB, et al. Chylous leakage after a laparoscopic livedonor nephrectomy: case report and literature review. Exp Clin Transplant 2016;14:338-40.

16. Shokeir AA, Gad HM, el-Diasty T. Role of radioisotope renal scans in the choice of nephrectomy side in live kidney donors. J Urol 2003;170:373-6. [CrossRef]

17. Peracha J, Hayer MK, Sharif A. Gender disparity in living-donor kidney transplant among minority ethnic groups. Exp Clin Transplant 2016;14:139-45. 